$J J M L L$

\title{
A Multimodal Discourse Analysis of Pictures in ELT Textbooks: Modes of Communication in Focus
}

\author{
Shafagh Ghoushchi*, Hooshang Yazdani, Hamidreza Dowlatabadi, Moussa Ahmadian \\ Department of English Language and literature, Arak University, Iran
}

Received on: 11-5-2020

Accepted on: 15-12-2020

\begin{abstract}
There is a tight nexus between visual literacy and textbook picture representations. This is of paramount importance when textbooks in general and ELT textbooks, in particular, are under question. To conduct a visual and verbal discourse analysis based on modes of communication, ELT textbook pictures were analyzed under the assumption that visual and verbal discourse interacts with reflected modes of communication. To this end, 50 ELT textbook pictures were used as the corpus and analyzed according to KvL's (2006) visual images analytical strategies in multimodal texts and Halliday's (1985) transitivity system for verbal analysis of textbook pictures. The analysis of multimodal resources revealed that the analyzed visual images were used to represent non-human images; close-up images, frontal images, left-right compositions were the most frequent visual modes in the selected pictures. In the case of verbal mode, the relational main-type and verbal minor-type level with $39 \%$ and $2 \%$ were the most and least frequent verbal strategies, respectively. The findings might have significant theoretical and pedagogical implications for scholars, L2 teachers, and ELT textbook designers to consider the potential of using multimodal resources for non-pedagogical purposes while integrating textbook visual images and verbal strategies to create meanings.
\end{abstract}

Keywords: Multimodal Discourse Analysis, Transitive System's Processes, Visual Images Interpretive Strategies, Modes of Communication, ELT Textbooks.

\section{Introduction}

The usage of picture and text in designing EFL coursebooks have recently been introduced into the global market, including that of Iran. Most available EFL coursebooks feature eye-catching images, pictures, cartoons, and photos that beg to be explored and draw in even the most reluctant learners. Although it may seem a superficial way of judging a book, the reality is that students' experience of using a book and having confidence in it is much affected by how it looks, and whether it contains appealing images and short sentences to describe the image. The reader's eyes meet pictures before texts and it is no secret that young readers' first impression is usually shaped by the book's appearance; hence, colorful pictures and alluring illustrations give rise to positive impressions and attitudes. But pictures can do even more than hook learners into the book. As the adage implies, pictures convey information more efficiently

๑๑ 2021 JJMLL Publishers/Yarmouk University. All Rights Reserved,

${ }^{*}$ Doi: https://doi.org/ 10.47012/jjmll.13.4.2

* Corresponding Author: sh-ghoushchi@phd.araku.ac.ir 
and effectively than words do. They can quickly and easily convey much detailed information in visible form; therefore, they contribute a lot to the readability and comprehensibility of a book.

Pictures and visual representations have a long history in instructional materials, and their positive value in second language acquisition and EFL has been documented. It is understood that using visuals in teaching results in a greater degree of learning. The concept of visual literacy is one specific type of literacy, which was first coined in 1969 by John Debes. According to Debes (1969), visual literacy is a group of vision competencies developed by seeing and at the same time integrating other sensory experiences to normal human learning. When these competencies are developed, they enable a visually literate person to discriminate and interpret the visible actions, objects, symbols natural or human-made which he encounters in his environment. Sinatra (1986) defines visual literacy as "the active model of experience with incoming visual information to get meaning".

Past decades have witnessed the trend of multimodality which involves multiple semiotic modes such as visual image, verbal language, and acoustic sound in human communication, as well as the mushroom development of SF-MDA (Multimodal Discourse Analysis) inspired by Halliday's (1994) Systemic Functional Linguistics. SF-MDA views diverse semiotic resources in terms of representational, interactive, and compositional tri-meta-functions, i.e., modeling visual representations of the material world, constructing the relations between viewers and what is viewed, and creating visual coherence, according to Kress and van Leeuwen (2006). Pedagogical materials cannot escape from this multimodality trend. Nowadays, textbooks (especially primary and secondary school textbooks) are full of colorful pictures, cartoons, and highlighted texts. Some are even equipped with multimedia supplementary materials (such as DVDs), which draw students' attention more easily, due to the synchronization of multiple modes.

Visual literacy of the learners in general and language learners, in particular, has been approached from a variety of perspectives to clarify the relationships between the signifier and the signified. Among them are studies elaborating on the relationship between visual literacy and textbook picture representations (Ahmadian \& Yazdani 2013; Razmjoo \& Jozaghi 2010). The previous studies included pictures as one of the modes in the study based on its reported affordances which confirm that textbooks serve L2 learners as facilitative tools in the learning process in different ways (Ball et al. 2015; Genesee \& Hamayan 2016).

Textbook pictures reportedly tap L2 learners' nonlinear dynamic motivation (Bahari 2018, 2019) and accelerate their cognitive processing by supporting mental model adaptation through creating a flexible linkage between input and task-oriented updates (Zhao et al. 2020). Despite the advantages mentioned above, there is a gap of research focusing on the semiotic modes of visual pictures in ELT textbooks. To bridge this gap, the present study elaborated on semiotic assets by drawing on multimodality and including static and dynamic assets by analyzing instructional ELT discourse (verbal discourse) and the picture-based instructional discourse (visual discourse). This multimodal approach tapping various semiotic modes (Van Leeuwen 2005) makes it possible to highlight the significance of the semiotic asset frameworks at contextualized and code-ployed levels (Baldry \& Thibault 2006), and in terms of 


\section{A Multimodal Discourse Analysis of Pictures in ELT Textbooks: \\ Modes of Communication in Focus}

components, style of typeface, shading immersion, etc. (Machin, 2007). Multimodality as an assessment gauge makes it possible to assess semiotic assets which are more perplexing than composed writings in terms of the rationale of sorted out courses of action, spatiality, and synchronization (Kress, 2003).

However, despite the reported affordances of multimodality in terms of facilitating language development (Dzekoe 2017; Lim \& Polio 2020; Vandommele et al. 2017), there is a gap in the literature in terms of the right sequence of multimodality, the right components to be incorporated, and several other dimensions that remain unattended. Several studies have attempted to bridge the gap, among them is the study conducted by Cimasko and Shin (2017) who included multimodal audiovisual resources to measure the participants' perceptions of video production tasks and another study was conducted by Jiang (2018) who used different instruments and patterns to investigate the same topic. In another study, Dzekoe (2017) explored the potential of posters as a multimodal resource and reported a significant positive contribution of posters in developing written discourse in terms of accuracy, complexity, and fluency. Multimodal resources including textbook images, reportedly facilitate visual thinking and improve L2 learners' communicational competence (Fernández-Fontecha et al., 2020), which reflects the significance of addressing multimodality in learning. Reportedly, multimodal discourse investigation informs us whether a picture succeeds at activating the reader's cognizance of the picture via linking the existing information and the fitting utilization of systems or not (Van Leeuwen \& Jewitt, 2001). Multimodality also provides information about visual materials at two levels: iconographic and iconological (see Figure 1). Iconographic level refers to the denotative interpretation of the visual materials via elucidation of conventional implications and iconological level, which refers to the elucidation of the ideological implications of the visual materials).

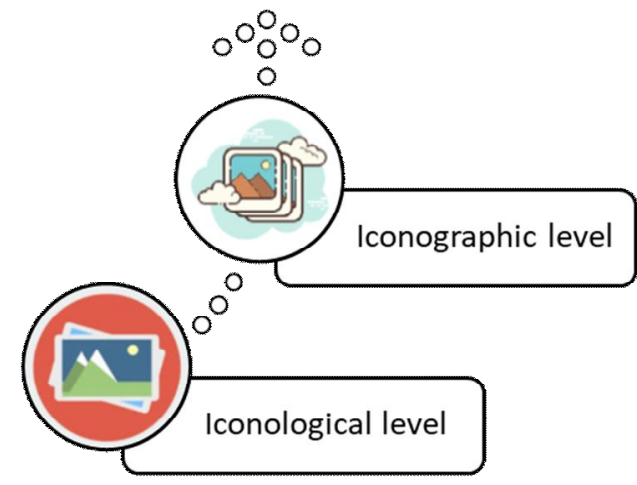

Figure 1: Multimodal Levels of Visual Material Analysis.

In line with previous studies, the current research aimed at analyzing the verbal and visual modes of pictures in Vision 1and 2 school-aided books through a descriptive-analytic design to collect the required data and conducted the appropriate data analysis concerning the following research questions:

RQ1: What are the most frequently observed sub-types of Halliday's (1985) transitivity system in the verbal analysis of textbook pictures? 
RQ2: What are the most frequently observed sub-categories of KvL's (2006) visual images interpretive strategies in the visual analysis of textbook pictures?

RQ3: How does visual and verbal discourse interact in EFL textbook pictures reflect modes of communication?

\section{Literature Review}

\section{Theoretical Framework}

Semiotics, as a research framework, has achieved noticeable significance in applied linguistics by attracting several scholars expounding on this area of interest from various perspectives and points of view. Among them, Mahdi and Gubeily (2018) contend that there is a significant relationship between semiotics and etymology. In this relationship, they contend that semiotics gives the correspondence of any message whatever or the exchange of any message whatever and the arrangement of signs, which underlies them. In the same line of thought, Zamani (2016) concerning the job of semiotics in language instruction, contends that it enables the students to build up their intellectual mindsets at all degrees of recognition. Semiotics can assume an exceptionally indispensable influence in the field of language learning and teaching. Senel (2007) accepts that semiotics facilitates the teaching/learning process by utilizing non-verbal communication, pictures, visuals, film-strips, video, photography, and so forth. With the assistance of semiotics, language learning turns out to be progressively beneficial and motivating. Semiotics can upgrade the exhibition of the understudies in all the four skills and parts of language learning. Semiotics is a broad territory, which is utilized in numerous fields, including training.

Semiotics, as per Hişmanoğlu (2006) is concerned about everything that can be utilized as a sign. A sign is everything that can be taken as altogether filling in for something different. Along these lines, it tends to contend that semiotics is related to whatever can be considered or deciphered as a sign. There are two models of semiotics, the dyadic model of Saussure (2000), and the triadic model of Peirce. The essential contrast between the perspectives on Saussure and Peirce is that Saussure's semiotics focuses on the semantic angles that principally focuses on setting up a connection between the vocal piece of the sign, that is the signifier, and its real piece, that is implied. On the other hand, Peirce manages semiotics from a philosophical point of view that is concerned with making a sort of relationship between the real world and nature (Massinbow and Rahayu 2001).

The theoretical framework of the study draws on KvL's (2006) visual image strategies (Figure 2) in multimodal texts and Halliday's (1985) transitivity system in the verbal analysis (Figure 3) of textbook pictures. This multimodal combination of theoretical designs made it possible to address both text and visual properties in textbook pictures. 
A Multimodal Discourse Analysis of Pictures in ELT Textbooks:

Modes of Communication in Focus

Kress and Van Leeuwen's (2006) mode of visual meaning

Figure 2: KvL's (2006) Framework for Visual Images Strategies

Representational: Relation between participants depicted Interactive:

Relation between image and viewer

Compositional:

Relation between elements of the text elements of the image
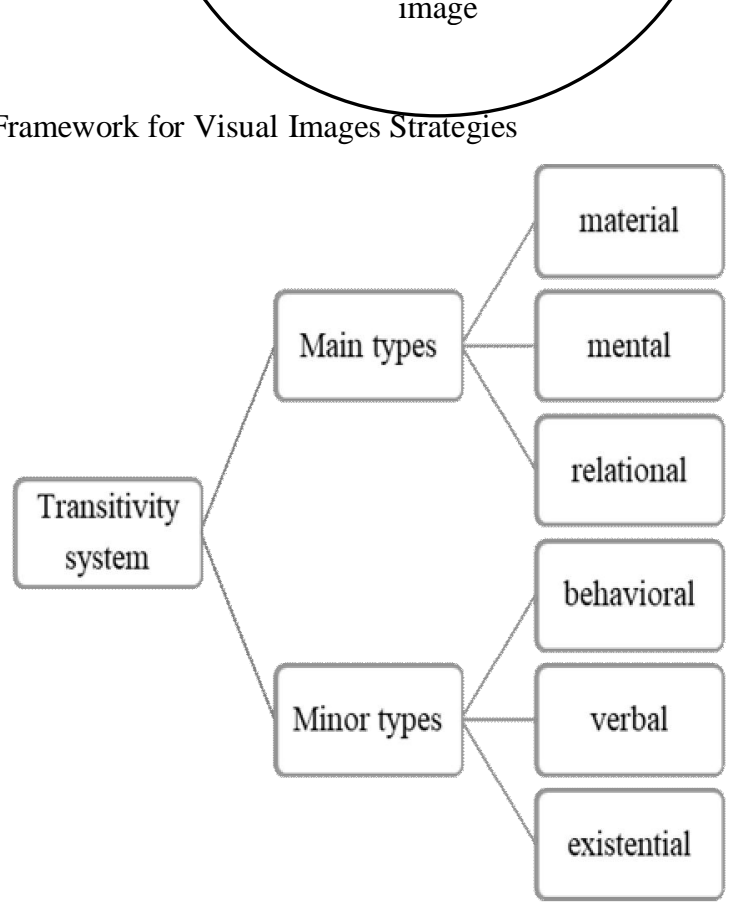

Figure 3: Halliday’s Framework (adapted from Halliday, 1985)

\section{Empirical Studies}

Semiotics-based studies in the field of applied linguistics have attracted several first/second language scholars. Among them is the study conducted by Mahdi and Gubeily (2018) who reported a significant relationship between semiotics and etymology.

Zamani (2016) confirmed the significant role of semiotics in language. Zamani contended that semiotics facilitates constructing intellectual mindsets during the recognition process. Senel (2007) reported that utilizing semiotics progressively benefits learners including training four language skills. 
Ghoushchi, Yazdani, Dowlatabadi, Ahmadian

Several scholars have confirmed the facilitative role of semiotics in developing the relationship between signifier and signified in instructional textbooks (Ahmadian et al. 2019; Hişmanoğlu 2006; McCullagh 2010; Massinbow \& Rahayu 2001; Razmjoo \& Jozaghi 2010; Tomlinson, 2011). Besides, Ahmadian and Yazdani (2013) confirmed the impact and nearness of past writings in the development of the present one which confirmed previous findings in the field (Booker 1996; Halliday 2003; Mahfouz 2013; Peck \& Coyle 2002; Sivandi Nasab \& Dowlatabadi, 2016). The effectiveness of pictures in textbooks for developing and reinforcing L2 instruction has been approached by several scholars who have positively confirmed the effectiveness of pictures in L2 instruction in a variety of vantage points (Amerian \& Khaivar 2014; Canning 1998; Canning-Wilson 1999; Mendoza \& Reese 2001). They all have confirmed that textbook pictures have the potential to bring the outside world into the L2 learning process and facilitate 12 learning process by increasing motivation and creating a learner-friendly instructional material (Elmiana 2019; Kress \& van Leeuwen 2006; Roohani \& Saeidfar 2013; Tahririan \& Sadri 2013; Zammit 2007).

Likwise, Moghtadi (2012) reported the effectiveness of visual pictures in EFL textbooks in terms of providing a fitting contribution to L2 learners following a study of three criteria of illustrative, upgrade reaction, and understudy produced to break down the capacity of four EFL textbooks for Iranian secondary schools. Anstey and Bull (2006) confirmed the pedagogical potential of visual images as a medium to enrich multimodal messages for L2 teaching purposes. In the same line of study, Serafini (2008) confirmed the effectiveness of visual pictures as an instructional tool in developing second language writing proficiency. In another study, Haiyan (2018) tested the applicability of Martinec and Salway's (2005) framework of image-text relations in school textbook discourse and adopts mixed methods by combining quantification of thirteen categories in Martinec and Salway's analytical framework with interpretations of the relations between visual images and verbal language in the six junior high school EFL textbooks to generalize multimodal trends in pedagogical discourse. The findings shed some light on cultivating students' multimodal literacy in the pedagogical context of Mainland China. In the same vein, Motschenbacher (2018) examined verbal and visual cultural indexes that allow for conclusions on the representation of native and non-native social actors and ENL, ESL, and EFL cultures.

Moreover, Joo et al. (2019) examined EFL textbooks as a compulsory primary school subject in South Korea. They analyzed whether and how the multimodal resources used in five EFL textbooks approved by the South Korean government for use in Grade 3 addressed the curriculum requirement to present English as an essential bridge connecting different countries. The critical multimodal content analysis of textbook characters and their interactions suggested that a general western bias and implicit support of native-speakerism were still existent in Korean EFL textbooks. Furthermore, Mughal and Awan (2017) exposed a biased representation of western and non-western cultures in visual materials. Their study of textbooks adopted for elite middle schools in Pakistan provided examples of how images and written text promote western culture and ideologies namely consumerism, environmentalism, and technological advancement while constructing 'Third World' and non-western values as undesirable. 


\section{A Multimodal Discourse Analysis of Pictures in ELT Textbooks: \\ Modes of Communication in Focus}

Additionally, Elmiana (2019) adopted the framework proposed by KvL to analyze visual images in Indonesian senior high school EFL textbooks, shed light on their functions, appropriateness and suitability for pedagogical purposes. The data covered all the visual images in the three EFL textbooks, a total of 232 images. The findings suggested that regarding gender bias and stereotypes males were more frequently portrayed than females ( $66 \%$ and $34 \%$ of images respectively).

Finally, Stewart and Roxy (2019) explored the potential of a multimodal classroom activity in which students' graffiti their textbooks to encourage elementary-age Korean EFL students to express themselves, engage critically with, and transform their English class materials. They conducted an action research project in three sixth-grade EFL classes and four third-grade EFL classes in a Korean elementary school. Participating students were instructed to choose a page in their English textbooks and graffiti it however they wished. The students were then surveyed, and their textbook graffiti was analyzed. Results demonstrated that Korean elementary students could use English in combination with other expressive modes to create graffiti that engaged with and transformed their textbook contents.

\section{Materials and Methods}

The Corpus

For the current study, Iranian EFL high school textbooks (i.e. Visions \& Prospects) were used. Then, 50 textbook pictures were randomly selected. It should be noted here that the study adopted a descriptiveanalytic design to collect the pictures as the data. Indeed, the unit of analysis in verbal mode was selected as the dependent or independent clause, and in visual mode, any picture containing a short verbal description was used as the research data.

\section{Assessments and Measures}

To analyze modes of communication in the visual discourse of textbook pictures from the social semiotic perspective, the study aims at identifying the ways the agents are represented in textbook pictures. Accordingly, 50 textbook pictures from Iranian EFL high school textbooks (Five samples are provided in Appendix A) were used as the corpus of the study, and the pictures were analyzed concerning Kress and Van Leeuwen (henceforth KvL) (2006) visual images interpretive strategies in multimodal texts, and Halliday's (1985) transitivity system for verbal analysis of textbook pictures.

The theoretical framework guiding the study was Kress and Van Leeuwen's (2006) grammar of visual design. The authors argue for "autonomy of images from verbal texts and postulate that images communicate meanings "through their specific forms and independently of words" (KvL 2006, 17).

To analyze modes of communication and the role and function of images in the visual discourse of textbook pictures from the social semiotic perspective, the study tried to identify the ways the agents were represented in textbook pictures. To this end, fifty textbook pictures were used as the corpus and analyzed concerning KvL's (2006) visual image strategies in multimodal texts. Besides, the verbal analysis of textbook pictures was done based on Halliday's framework (1985) (see Figure 2). Under Halliday's Systemic Functional Grammar, the Metafuncion of language serves the user as the textual message, the 
interpersonal metafunction serves the user as the exchange and the ideational metafunction serves the user as the representation. The present study applied the ideational function as part of the transitivity system to analyze the verbal descriptions of pictures used in ELT textbook pictures under the study. The obtained data from two frameworks were categorized and codified in a tabular format (see Table 1) to facilitate data analysis.

Table 1: Tabular Data Codification \& Categorization.

\begin{tabular}{ll}
\hline Category type & Codification options \\
\hline Text-image relationship & Direct \\
& Indirect \\
& No association \\
\hline Modes and realizations of visual meanings & Representational \\
& Interactive \\
& Compositional \\
\hline Ideational functions & Main type-Material \\
& Main type-Mental \\
& Main type-relational \\
& Minor type-behavioral \\
& Minor type-verbal \\
& Minor type-existential \\
\hline
\end{tabular}

\section{Results}

The results of the study concerning the first research question revealed that the most and least frequent representations of modes of communication in the discourse of EFL textbook pictures at the verbal level were at relational main-type and verbal minor-type level, respectively. The frequency of each minor and main level in 50 analyzed clauses were shown in the following table.

Table 2: Modes of Communication in Verbal Discourse of Textbook Pictures.

\begin{tabular}{lccccccc}
\hline & \multicolumn{6}{c}{ Type of Process } \\
\cline { 2 - 7 } Clauses & Material & Mental & Relational & Verbal & Behavioral & Existential \\
NO & 50 & 13 & 8 & 16 & 1 & 4 & 8 \\
\hline
\end{tabular}

According to Table 4, the analysis of the textbook pictures and their corresponding texts revealed that material, mental, existential, and behavioral levels included 13, 8, 8, and 4 examples, respectively. The frequency percentage of each main and minor level was presented in figure 3.

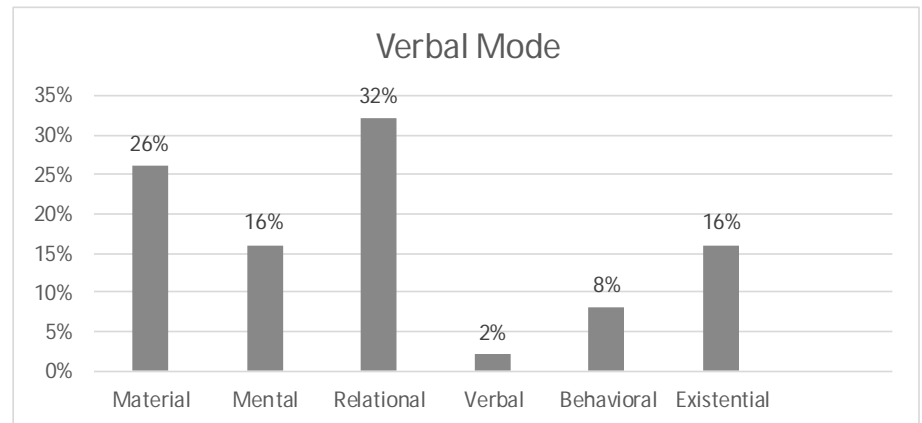

Figure 3: The Frequency Percentage of Verbal Levels Based on Halliday Classification 


\section{A Multimodal Discourse Analysis of Pictures in ELT Textbooks: \\ Modes of Communication in Focus}

The analysis of the textbook pictures and their corresponding texts revealed that the most frequently observed sub-types of Halliday's (1985) transitivity system in the verbal analysis of textbook pictures were mainly relational (32\%) as a main-type ideational function. This result shows that the EFL textbooks' pictures serve to depict things that exist without utilizing features of it to link the signifier with the signified. In other words, the pictures under the study are mainly mediums to transfer some ideological notions (i.e. extra-linguistic concepts) to L2 learners rather than linguistic functions (i.e. purposes for using language).

Concerning the second research question, the researcher employed KvL's (2006) visual image strategies at three different levels; representational, interactive, and compositional level to observe the frequency of each level. The frequency of each level and sub-level were shown in table 3 .

Table 3: Visual Images Framework based on KvL's (2006) Strategies.

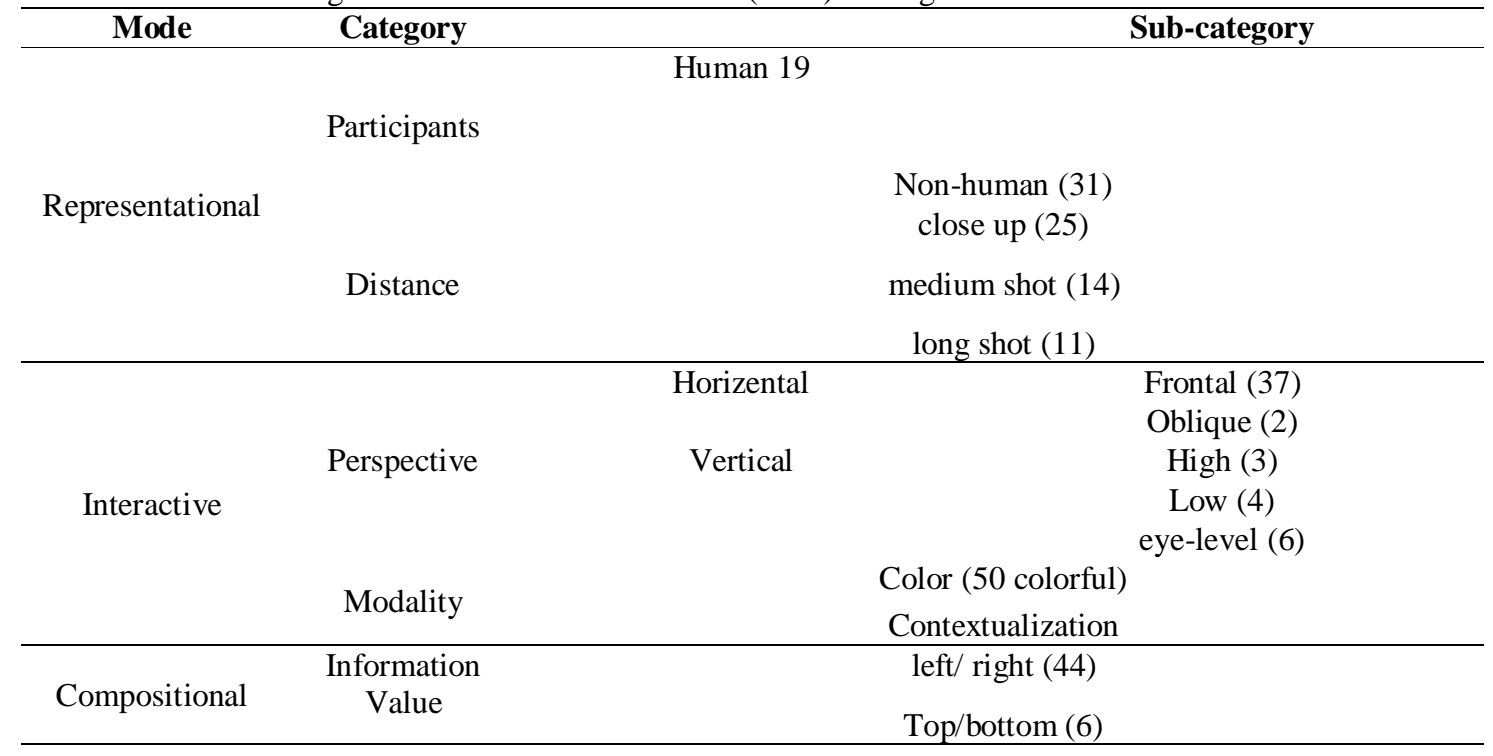

According to $\mathrm{KvL}$ (2006), the representational mode relates to how visual structures represent people, animals, and places, their actions, experiences, and relationships, as well as the characteristics and qualities attributed to them. Thus, to analyze this mode of meaning-making in the images under study, in the first place the type (in terms of being human or non-human) and frequency of presence of the participants in the images were figured out. Then the relationships and characteristics of the participants were investigated to reveal the covert meanings (e.g., sociocultural connotations, gender stereotypes) represented by the images. The frequency and percentage of the representational mode were shown in figure 4. 
Ghoushchi, Yazdani, Dowlatabadi, Ahmadian

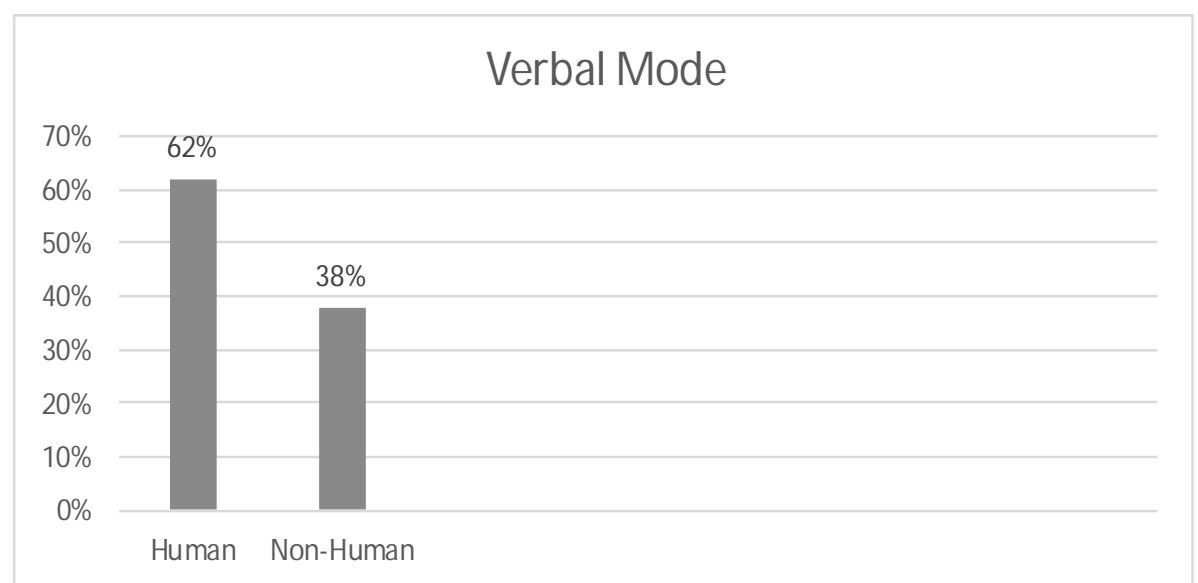

Figure 3: The Frequency Percentage of Representational Mode.

According to KvL (2006), the interactive mode of visual meaning refers to ways in which the visuals address, communicate, and connects with the viewers. The image-viewer interactions in the images under study were analyzed based on these three aspects: distance, perspective, and modality. The frequency and percentage of the interactive mode were shown in figure 5.

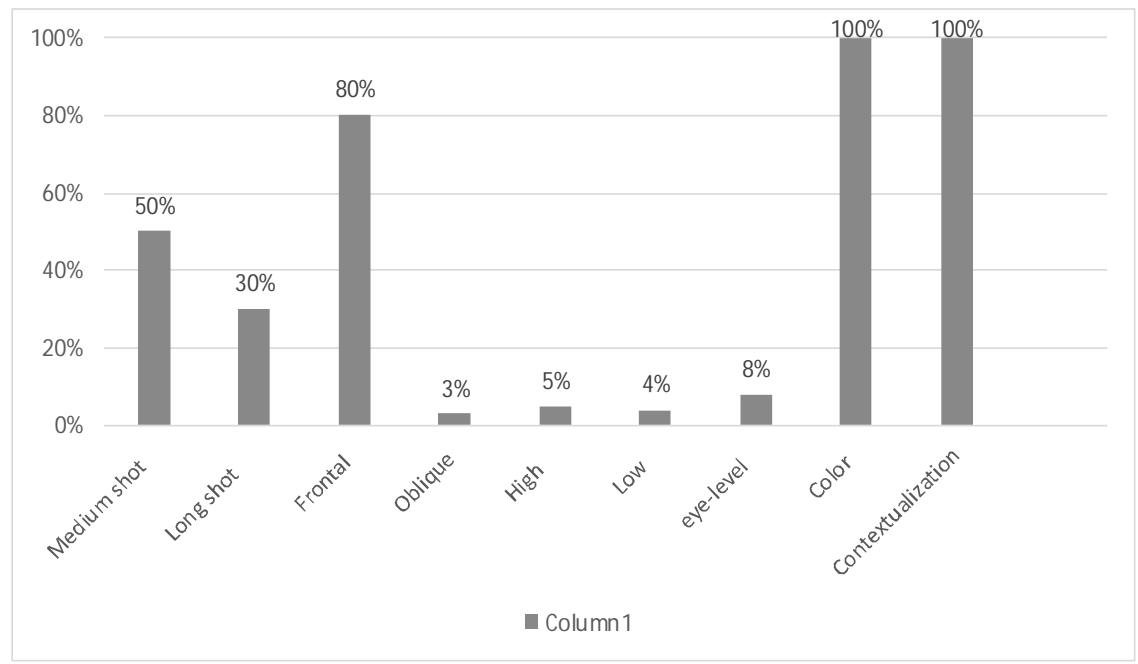

Figure 4: The Frequency Percentage of Interactive Mode.

Distance (or social distance) relates to the size of the visual frame. KvL (2006) suggest that the amount of the participant's body shown in the visual frame determines the degree of social distance and intimacy between the participants and the viewers. More specifically, a close shot which shows the head and shoulders of the participants implies an intimate relationship, a medium shot which cuts off participants approximately at the waist conveys a familiar or social connection, and a long shot frame which shows a full human figure demonstrates that the social relation between the visual and the viewer is a public, largely impersonal one. 
A Multimodal Discourse Analysis of Pictures in ELT Textbooks:

Modes of Communication in Focus

Perspective specifies the degrees of involvement and power. This is realized through various choices of visual horizontal and vertical angles. Put differently, the perspective or point of view from which viewers and participants interact denotes different levels of involvement, abstraction, power, or inferiority. More specifically, $\mathrm{KvL}$ (2006) proposes that along the horizontal axis, the frontal plane associates with an attitude of involvement whereby the viewer is invited to become part of the world depicted in the image. On the other hand, the use of an oblique angle conveys a sense of detachment and connotes that what the viewer sees is not part of his or her world. The vertical axis and its variants (e.g. high, low, or eye level) signify power at different levels and in different relationships (KvL 2006). For example, whenever a represented participant is pictured from a high angle, he or she is seen from the perspective of inferiority to the viewer. Conversely, if the represented participant is shown from a low angle, he or she is said to have power over the viewer. Finally, if the image is at eye-level, it encodes a relation of equality between the viewer and the participants.

Modality refers to ways of modulating reality in visual representations. KvL (2006) define modality as the criteria against which viewers express judgments about the truth or credibility of visual structures. According to KvL (2006), two critical factors in credibility or naturalistic modality of visuals are color and contextualization. They suggest that the use of color is of great importance in expressing visual modality in that the more the color is abstracted from naturalistic presentations, the lower is the modality. They contend that for visuals to have high modality, they should have: high color saturation rather than black and white; diversified colors rather than monochrome; and modulated colors rather than unmodulated flat colors. Naturalistic modality is influenced by the contextualization of the image as well; that is, by its background and the extent to which the settings are represented in detailed and itemized manners. Generally speaking, KvL (2006) maintains that the presence of background in an image increases its modality from a naturalistic perspective whereas the absence of background lowers it.

The analysis of the textbook pictures and their corresponding texts in response to the fourth research question revealed that visual and verbal discourse interacts in EFL textbook pictures reflect an indirect mode of communication ( $\mathrm{PCT}=48 \%$ ). This finding as displayed in figure 8 informs us of the main mode of communication: an indirect text-image relationship which reflects the failure of the textbook designers at selecting the right pictures to serve L2 teaching purposes The obtained results show that $24 \%$ of the analyzed textbook pictures have no association with the corresponding text, which shows that one-fourth of the analyzed pictures lack pedagogical relevance and only $28 \%$ of the whole corpus was recognized as relevant.

KvL (2006) suggest that if verbal-visual compositions follow a left-right structure, the left-hand element conveys the meaning of a familiar and self-evident piece of information (or the 'Given') and the right-hand element of the layout demonstrates a piece of new information which should be attended to (or the 'New'). On the other hand, the information value of atop/bottom positioning carries different features in that the upper section of a verbal-visual composition is believed to contain what is presented as 'Ideal' (idealized or generalized essence of information) whereas the lower section what is 'Real' (more practically oriented information). 


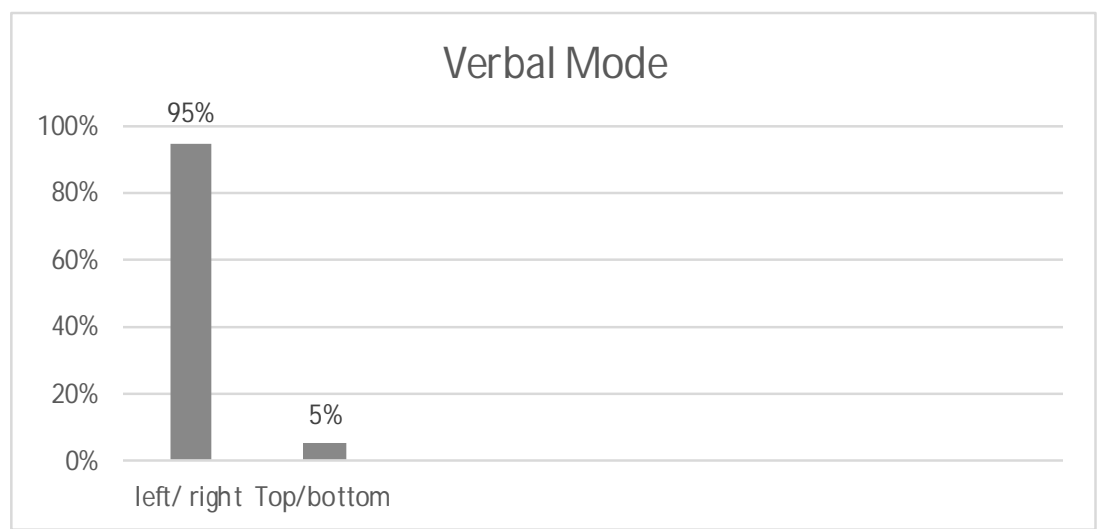

Figure 5: The Frequency Percentage of Compositional Mode.

\section{FREQUENCY OF TEXT-IMAGE RELATIONSHIP AS MODES OF COMMUNICATION}

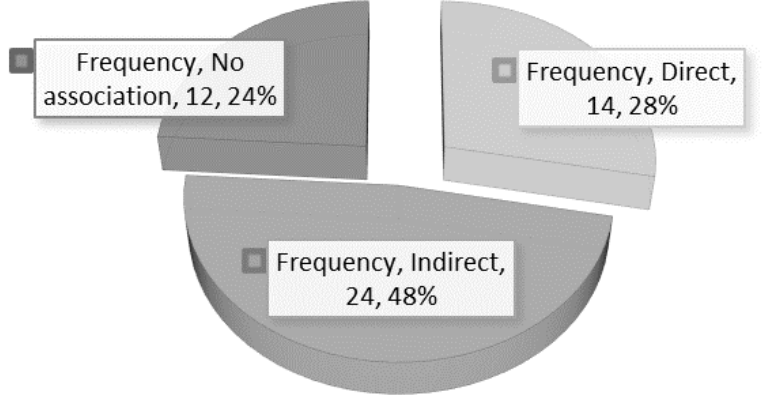

Figure 6: Frequency of Text-Image Relationship as Modes of Communication.

\section{Discussion}

The obtained results show the failure of the analyzed pictures of the EFL textbooks in ensuring meaning-image cohesion as well as developing linguistic competence. The pictures were designed based on different representational, interactive, and compositional modes. This activity can contaminate the instructional material by distracting the learners' attention from pedagogical objectives such as providing learners with images signifying real-world situations.

The obtained results significantly differ from those of another study conducted in Indonesia on EFL textbook pictures by Setyono and Widodo (2019). A close look reveals that they have observed a multicultural approach taken by the textbook designers to select pictures that contrast with the observed monocultural approach of incorporating visual materials in the present study. This finding contradicts the results reported by Weninger and by Weninger and Kiss (2013), who reported opposite results concerning the pictures' observed functions in textbooks. 
A Multimodal Discourse Analysis of Pictures in ELT Textbooks:

Modes of Communication in Focus

However, the findings are partially in keeping with the results reported by Vungthong et al. (2017) who emphasized the need to consider the variety of semiotic affordances and meaning-making limitations, and potentials images for language teaching purposes. The study's findings confirm the results reported by Kusumaningputri and Widodo (2018) who emphasized the gap between the multicultural features of instructional materials and the pedagogical goals. The findings are partially consistent with the results reported by Sevensson (2020) who explored the emotional dimension in text and image in Swedish textbooks. The study illustrated similarities and differences in terms of visual and verbal meaning-making constructs and reported the significance of drawings styles and their potential impacts on different age groups. Drawing on the theory of mind capacities, the intertextual and symbolic aspects were investigated concerning shifting emotions' dynamicity. The findings are consistent with the study conducted by Andrä et al. (2020) who confirmed the significance of incorporating pictures into pedagogy and developing L2 learning. They explored the impact of pictures and gesture-enriched learning on vocabulary learning and reported that both variables enhanced L2 learners' learning to a significant extent and highlighted the positive impact of incorporating visual images in developing perceptual recognition of the input confirming the previous results (Konomi 2014; Mayer et al. 2015; Yildirim \& Jacobs 2012).

Multimodal analysis of the EFL textbooks' verbal and visual interactions revealed a mismatch between signifier and signified in terms of the pedagogical functions. The theoretical implication of the study is the need to ensure the relevance of instructional mediums and instructional objectives. The next theoretical implication is the need to take a multi-cultural approach in selecting audiovisual materials to avoid mono-culturalism. The study revealed the need for a comparative theoretical framework that can delve into influential factors that influence the transfer of meaning in picture-learner interactions at cognitive and visual levels. Further analysis in terms of determining the right sequence of multimodal resources seems to be highly critical to improving the efficacy of multimodality in learning and the learners' perception of its effectiveness. To this end, developing and designing tasks that integrate pragmatic L use and learner needs might be a promising trend of study for future research in the field. The next significant theoretical implication of the study is the need to incorporate collaboration in modes of communication in the visual and verbal discourse of EFL textbook pictures and benefit from the reported advantages of collaborative L2 learning (Storch 2005; Wigglesworth \& Storch 2009; Zhang 2019).

Similar to any other research, several limitations influenced the outcomes of the current study. The multimodal discourse analysis performed in this study was based on two specific frameworks and interpreted the observed data per their guidelines; it was possible that the same books can be analyzed based on other frameworks. Moreover, this study was limited to the processing capacity, and it is possible that the author missed some information when the information density is high. Another limitation of the study was the lack of direct and easy access to the authors and editors of the textbooks under the study, who could provide more information concerning their intentions behind selecting one picture rather than the other. 


\section{Conclusion}

Based on the obtained results via multimodal analysis of the verbal and visual interaction of EFL textbook pictures, it can be safely concluded that the pictures were mainly designed with a different range of representational, interactive, and compositional modes. It can be concluded that the inclusion of mono-cultural pictures signifying instructional meanings other than L2 teaching-oriented meaning has extra-linguistically affected the textbooks under the study. The use of non-instructional visual materials (materials with no association which formed $24 \%$ of the corpus) and partially-instructional visual materials (materials with an indirect association which formed $48 \%$ of the corpus) betokens inappropriate and deficient inclusion of pictures for the L2 teaching-learning purposes

The corpus analysis revealed that the pictures fail to construe the paradigm of experience and logical relations as an instance of relational between image and the intended function by being used for visual functions rather than pedagogical ones. The next instance of deficiency observed in the corpus under study was the failure of the adopted textbook pictures to relate learner group members as an interpersonal function. Therefore, the main implication of this finding for text designers is the need to select pictures more rigorously to avoid including pictures that fail to create cohesion and coherence at ideational and interpersonal levels. Accordingly, to facilitate the learning process as the core goal of instruction, L2 teachers are suggested to incorporate textbook visual images to improve visual thinking as a scaffolding strategy. The provision of relevant visual images can help learners understand the semantic relationships of the input's complex components via visual elaboration. Utilizing visual images as a multimodal resource can potentially accelerate linking ideational meaning of the visual-image-embedded-input and the original learning content (Fernández-Fontecha et al. 2020). It is suggested that future studies be conducted with more corpus of the picture representations. 
A Multimodal Discourse Analysis of Pictures in ELT Textbooks:

Modes of Communication in Focus

\section{تحليل الخطاب متعدد الوسائط للصور باللفة الإنجليزية من خلال كتب مدرسية \\ بلفة أجنبية مع التركيز على طرق الاتصال \\ شفق قوشجي، هوشنك يزداني، حميد رضا دولت ابادي، موسى احمديان \\ قسم اللغة الإنجليزية وآدابها، جامعة أرال، إيران \\ الملخص}

تمت دراسة وتحليل صور الكتب المدرسية لمادة الغة الإنجليزية في هذا البحث من أجل تحليل الخطاب البصري واللفظي

بالتركيز على الأوجه التواصلية. والفرضية التي تقول بأنّ تفاعلات الخطاب البصري واللفظي تعكس الأوجه التواصلية، قد أُخذت

بعين الاعتبار، ومن أجل تحقَق هذا الهدف، استخدمت استراتيجية تفسير الصور المرئية لـ"ليو" (2013) للتحليل البصري

ونظام هاليدي التحليلي (1985) للتحليل اللفظي لصور وهوامش الكتب. وحسب المعلومات التي توصّل إليها البحث إن الصور

المرئية التّي تمت دراستها وتحليلها باستخدام الأسـاليب والطرق المشار إليها أعلاه، قد استُخدمت بشكل غير مباشر لبيان المفاهيم الإيديولوجية المختارة وعلاقة المظاهر برموزها. والتحليل متعدد الأوجه لصور الكتب المدرسية قد بيّن أنّ الصور المستخدمة في الكتب قد ساهمت كوسيط في نقل بعض المفاهيم الإيديولوجية أحادية الثقافة إلى متعلّمي اللفة الثانية وهذا التأثير يتجاوز الأداء اللغوي متعدد الثقافي في عالم الواقع. هذه النتائج تساعد بشكل ملحوظ الثؤون النظرية والتعليمية لمعلّمي الإنجليزية بوصفها اللفة الثانية وكذلك يساعد مصمّمي الكتب المدرسية التّي تتمّ دراستها في هذا البحث.

الكلمات المفتاحية: تحليل الخطاب متعدد الأوجه، عمليات النظام الانتقالي، استراتيجيات تفسير الصور، الأوجه التواصلية، الكتب المدرسية لتعليم اللغة الثانية. 
Ghoushchi, Yazdani, Dowlatabadi, Ahmadian

\section{References}

Amini, Seyyedeh-Mahsa, Moussa Ahmadian, Hooshang Yazdani, and Hamid-Reza Dowlatabadi. "Multiple Intelligences (MI) Representation in Prospect Series and the MI Profile of Iranian Junior High School Students: A Compatibility Perspective. International Journal of English Language \& Translation Studies 7 (2): 52-62. DOI.org/11.1207/s12559-018-9506-3.

Ahmadian, Moussa, and Hooshang Yazdani. 2013. A Study of the Effects of Intertextuality Awareness on Reading Literary Texts: The Case of Short Stories." Journal of Educational and Social Research 3 (2): 155. DOI:10.5901/jesr.2013.v3n2p155.

Amerian, Majid, and Alimorad Khaivar. 2014. Textbook Selection, Evaluation and Adaptation Procedures. International Journal of Language Learning and Applied Linguistics World 6 (1): 523533. DOI.org/10.1007/s10805-018-9316-3.

Andrä, Christian, Brian Mathias, Anika Schwager, Manuela Macedonia, and Katharina von Kriegstein. 2020. Learning Foreign Language Vocabulary with Gestures and Pictures Enhances Vocabulary Memory for Several Months Post-Learning in Eight-Year-Old School Children. Educational Psychology Review 32 (3): 815-850. DOI.org/10.1007/s10648-020-09527.

Anstey, Michèle, and Geoff Bull. Teaching and Learning Multiliteracies: Changing Times, Changing Literacies. International Reading Association. 800 Barksdale Road, PO Box 8139, Newark, DE 19714-8139, 2006.

Bahari, Akbar. 2018. Sacred Text Motivation for General L2 Learners: A Mixed Methods Study. Journal of Academic Ethics 16 (4): 377-407. DOI.org/10.1007/s10805-018-9316-3

Baldry, Anthony, and Paul J. Thibault. 2006. Multimodal Transcription and Text Analysis (London: Equinox). Developing Multimodal Texture 55.

Ball, Phil, Keith Kelly, and John Clegg. 2016. Putting CLIL into Practice: Oxford Handbooks for Language Teachers. Oxford University Press.

Canning, Christine. 1997. Theoretical use of Visuals." C. Canning \& J. Koester, Illustrated Visual Aids for Academic English 1 (1): 2-4.

Canning, Christine. 1998. Visual support and language teaching. TESOL Arabia News 5 (4): 3-4. DOI:11.1580/14681366.2019.2054411.

Cimasko, Tony, and Dong-shin Shin. 2017. Multimodal Resemiotization and Authorial Agency in an L2 Writing Classroom. Written Communication 34 (4): 387-413.

Debes, John L. 1969. The loom of visual literacy--An overview. Audiovisual Instr.

Dzekoe, Richmond. 2017. Computer-Based Multimodal Composing Activities, Self-Revision, and L2 Acquisition Through Writing. Language Learning \& Technology 2 (2): 73-95. DOI.org/10.1080/095 40253.2014.91640 0.

Elmiana, Dewi Satria. 2019. Pedagogical Representation of Visual Images in EFL Textbooks: A Multimodal Perspective. Pedagogy, Culture \& Society 27 (4): 613-628. DOI:11.1080/10048 1366.2019.1569550. 
A Multimodal Discourse Analysis of Pictures in ELT Textbooks:

Modes of Communication in Focus

Fernandez-Fontecha, Almudena, Kay L. O’Halloran, Peter Wignell, and Sabine Tan. 2020. Scaffolding CLIL in the Science Classroom via Visual Thinking: A Systemic Functional Multimodal Approach. Linguistics and Education 55: 100788. DOI.org/10.1016/j.linged.2019.100788

Genesee, Fred, and Else Hamayan. 2016. CLIL in Context Practical Guidance for Educators. Cambridge University Press.

Haiyan, Lai. 2018. Image-Text Relations in Junior High School EFL Textbooks in China: A MixedMethods Study. Journal of Language Teaching and Research 9 (6): 1177-1190.. DOI: http://dx.DOI.org/10.17507/jltr.0906.07.

Halliday, Michael. Alexander Kirkwood, and Christian MIM Matthiessen. 2013. Halliday's introduction to functional grammar. Routledge.

Hişmanoğlu, Murat. 2005. Semiotic elements and Difficulties in Teaching Vocabulary Items. Dil Dergisi 128: 51-68.

Jiang, Lianjiang. 2018. Digital Multimodal Composing and Investment Change in Learners' Writing in English as a Foreign Language. Journal of Second Language Writing 40: 60-72. DOI.org/10.1016/j.jslw.2018.03.002.

Joo, Sun. Jung, Alice Chik and Emilia Djonov. 2019. The construal of English as a Global Language in Korean EFL Textbooks for Primary School Children. Asian Englishes 22 (1): 68-84. DOI:10.1080/13488678. 2019.1627636.

Konomi, Dorela Kacauni. 2014. Using Visual Materials in Teaching Vocabulary in English as a Foreign Language Classrooms with Young Learners. Proceedings of the international conference on new perspectives in science education, pp. 256-260. Webster.

Kress, Gunther. 2003. Literacy in the new media age. Routledge.

Kress, Gunther and Theo Van Leeuwen. 2006. The Grammar of Visual Design (2ndeds)." London \& New York: Routledge. Taylor Francis Group.

Kusumaningputri, Reni, and Handoyo Puji Widodo. 2018. Promoting Indonesian University Students' Critical Intercultural Awareness in Tertiary EAL Classrooms: The Use of Digital PhotographMediated Intercultural Tasks. System 72: 49-61. DOI:10.1016/j.system.2017.10.003.

Sipe, Lawrence R. 1998. How Picture Books Work: A Semiotically Framed Theory of Text-Picture Relationships. Children's Literature in Education 29 (2): 97-108. DOI.org/10.1023/ A:1022459009182.

Lim, Jungmin, and Charlene Polio. 2020. Multimodal Assignments in Higher Education: Implications for Multimodal Writing Tasks for L2 Writers. Journal of Second Language Writing 47: 100713. DOI.org/10.1016/j.jslw.2020.100713.

Liu, Jing. 2013. Visual Images Interpretive Strategies in Multimodal Texts. Journal of Language Teaching \& Research 4 (6).

Machin, David. 2007. Introduction to multimodal analysis. London: Hodder 
Ghoushchi, Yazdani, Dowlatabadi, Ahmadian

Mahdi, Hassan Saleh, and Mohammed Ahmed Ibraheem Gubeily. 2018. The Effect of Using Bizarre Images as Mnemonics to Enhance Vocabulary Learning. Journal of Social Studies 24 (1): 113-135. DOI.org/10.20428/JSS.24.1.5

Mahfouz, Adel Refaat. 2013. A Critical Discourse Analysis of the Police News Story Framing In Two Egyptian Newspapers before January 25 Revolution." European Scientific Journal 9 (8). DOI: 10.1111/ijal.12237.

Masinambow, E. K. M., and Rahayu S. Hidayat. 2001. Semiotik: Mengkaji tanda dalam artifak. Jakarta: Balai Pustaka.

Mayer, Katja M., Izzet B. Yildiz, Manuela Macedonia, and Katharina von Kriegstein. 2015. Visual and Motor Cortices Differentially Support the Translation of Foreign Language Words. Current Biology 25 (4): 530-535.

McCullagh, Marie. 2010. An initial Evaluation of the Effectiveness of a Set of Published Materials for Medical English. Research for Materials Development in Language Teaching: Evidence for Best Practice: 381-393.

Mendoza, Jean, and Debbie Reese. 2001. Examining multicultural picture books for the early childhood classroom: Possibilities and pitfalls." Early Childhood Research \& Practice 3 (2): n2. DOI.org/10.1007/s12119-018-9526-2.

Moghtadi, Laleh. 2013. Visual Elements Used in Iran EFL High School Textbooks. International Journal of Foreign Language Teaching and Research 1 (1): 45-56. DOI: 11.5239/ijal.120089.

Motschenbacher, Heiko. 2018. Non-Nativeness as a Dimension of Inclusion: A Multimodal Representational Analysis of EFL Textbooks." International journal of applied linguistics 29 (3): 285-307. DOI: 10.1111/ijal.12237.

Mughal, Nazak Hussain, and Muhammad Safeer Awan. 2017. Ideo-Cultural Hegemony of EuroAmericans: Analysis of Presentation of Different Cultures in ELT Books in Pakistan. NUML Journal of Critical Inquiry 15 (2): 57-X. DOI: 11.1255/100875986.2089.1540089.

Peck, John, and Martin Coyle. 2002. Literary Terms and Criticism. 3rd edition. New York: Pargrave McMilan.

Razmjoo, Seyyed Ayatollah, and Zahra Jozaghi. 2010. The Representation of Multiple Intelligences Types in the Top-Notch Series: A Textbook Evaluation." Journal of Pan-Pacific Association of Applied Linguistics 14 (2): 59-84. DOI: 10.16875/stem.2019.20.2.48.

Roohani, Ali, and Ala Saeidfar. 2013. A Critical Evaluation of Visual Elements in Iranian Junior High School English Textbooks. Journal of Faculty of Letters and Humanities 8 (28): 80-96. DOI.org/10.1080/09540 253.2015.1102584.

Andrews, Richard, Mark Sadoski, and Allan Paivio. 2001. Imagery and Text--A Dual Coding Theory of Reading and Writing/Response. British Journal of Educational Psychology 72: 147.

Şenel, Müfit. 2007. The Semiotic Approach and Language Teaching and Learning. Journal of Language and Linguistic Studies 3 (1): 117-132. 
A Multimodal Discourse Analysis of Pictures in ELT Textbooks:

Modes of Communication in Focus

Serafini, Frank. 2008. The Pedagogical Possibilities of Postmodern Picturebooks. Journal of Reading. DOI.org/10.1504/IJCEELL.2011.040197.

Setyono, Budi, and Handoyo Puji Widodo. 2019. The Representation of Multicultural Values in the Indonesian Ministry of Education and Culture-Endorsed EFL Textbook: A Critical Discourse Analysis. Intercultural Education 30 (4): 383-397.DOI: 10.1080/14675986.2019.1548102.

Svensson, Birgitta. 2020. The enacting of Emotions in Two Picture Books: Interpretations through a Multimodal Discourse Analysis. International Journal of Language Studies 14 (2). DOI.org/10.1017/S0272263100015047.

Sinatra, Richard. 1986. Visual Literacy Connections to Thinking, Reading and Writing. Charles C. Thomas, Publisher, 2600 South First St., PO Box 4709, Springfield, IL 62708-4709.

Sivandi, Zohre, and Hamid Reza Dowlatabadi. 2016. A Critical Discourse Analysis on Newspapers: The Case Study of Nuclear Program of Iran. International Journal of Research Studies in Education 5 (2): 93-103. DOI.org/10.1111/j.1467-9922.2009.00528.x.

Gray, Stewart, and Roxy Lee. 2019. Textbook Graffiti as a Critical, Multimodal Classroom Activity for Korean Elementary EFL Students. STEM Journal 20 (2). DOI: 10.16875/stem.2019.20.2.43.

Storch, Neomy. 2005. Collaborative Writing: Product, Process, and Students' Reflections. Journal of second language writing 14 (3): 153-173. DOI.org/10.1016/j. jslw.2005.05.002

Tahririan, Mohammad Hassan, and Elham Sadri. 2013. Analysis of Images in Iranian High School EFL Course Books. Iranian Journal of Applied Linguistics 16 (2): 137-160.

Van Leeuwen, Theo, and Carey Jewitt, 2001. eds. The handbook of visual analysis. Sage.

Van Leeuwen, Theo. 2005. Introducing Social Semiotics. Psychology Press.

Vandommele, Goedele, Kris Van den Branden, Koen Van Gorp, and Sven De Maeyer. 2017. In-School and Out-Of-School Multimodal Writing as an L2 Writing Resource for Beginner Learners of Dutch." Journal of Second Language Writing 36: 23-36. DOI.org/10.1016/j.jslw.2017.05.010

Vungthong, Sompatu, Emilia Djonov, and Jane Torr. 2017. Images as a Resource for Supporting Vocabulary Learning: A Multimodal Analysis of Thai EFL Tablet Apps for Primary School Children." Tesol Quarterly 51 (1): 32-58. DOI: 10.1002/tesq.274

Weninger, Csilla, and Tamas Kiss. 2013. Culture in English as a Foreign Language (EFL) Textbooks: A Semiotic Approach. TESOL quarterly 47 (4): 694-716.

Wigglesworth, Gillian, and Neomy Storch. 2009. Pair Versus Individual Writing: Effects on Fluency, Complexity And Accuracy. Language Testing 26 (3): 445-466.

Yildirim, Ilker, and Robert A. Jacobs. 2012. A Rational Analysis of the Acquisition of Multisensory Representations. Cognitive science 36 (2): 305-332. DOI.org/10.3758/BF03195564.

Zamani, Sirvan. 2016. Semiotics and Language Teaching (Teaching English to Kurd Students). World Scientific News 42: 293-305. DOI.org/10.1111/j.1540-4781.1996.tb01613.x.

Zammit, Katina. 2007. Popular Culture in the Classroom: Interpreting and Creating Multimodal Texts. Advances in language and education: 60-76. 
Ghoushchi, Yazdani, Dowlatabadi, Ahmadian

Zhang, Meixiu. 2019. Towards a Quantitative Model of Understanding the Dynamics of Collaboration in Collaborative Writing. Journal of second language writing 45: 16-30. DOI.org/10.1016/j.jslw. 2019.04.001

Zhao, Fang, Wolfgang Schnotz, Inga Wagner, and Robert Gaschler. 2020. Texts and Pictures Serve Different Functions in Conjoint Mental Model Construction and Adaptation. Memory \& cognition 48 (1): 69-82. DOI.org/10.3758/s13421-019-00962-0 
A Multimodal Discourse Analysis of Pictures in ELT Textbooks: Modes of Communication in Focus

\section{Appendix A.}

\section{No. Picture}

1

The children went to school

by bus yesterday.

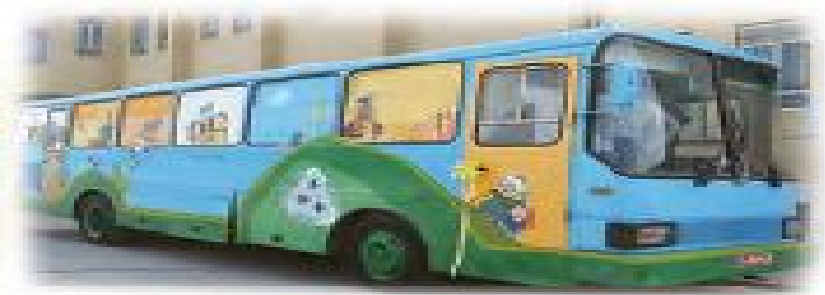

2

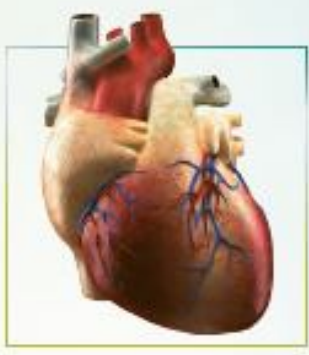

The heart pumps blood round the body.

3

She feels happy. 
Ghoushchi, Yazdani, Dowlatabadi, Ahmadian

4

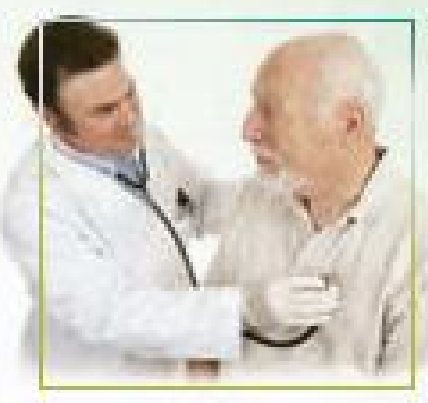

The doctor is listening to my grandfather's heartbeat.

5

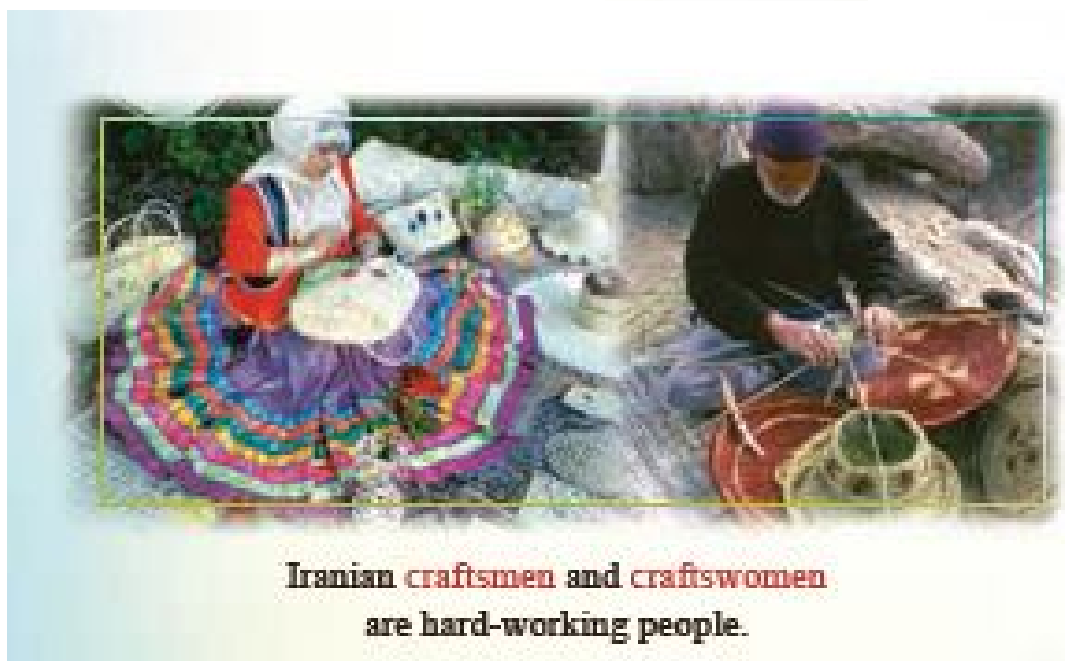

